\title{
The Association of Railway Industrial Occupational Health Practitioners (ARIOPS) annual general meeting
}

\author{
Dr Paul Grant reports from the National Railway Museum, York, 16th October, 2015
}

I was delighted to be able to attend the annual general meeting of The Association of Railway Industrial Occupational Health Practitioners (ARIOPS), in the very pleasurable setting of York. The major topic for discussion and debate was the effect of diabetes on safety critical work and railway workers.

This is currently a somewhat controversial subject amongst train operating companies and bears comparison with other professions such as police pursuit drivers, paramedics, firemen, coastguards and even civil airline pilots: all have used the Disability Discrimination Act (2010) to challenge employers and demonstrate that, despite the use of insulin treatment, they are safe and stable and fit enough to perform all manner of safety critical roles that had previously been closed to them. Two recent articles in the second best UK diabetes journal have touched on this, 1,2 as well as a recent debate in the Lancet $^{3}$ on whether experts would be happy taking a flight in a plane piloted by an individual with type 1 diabetes.

Dr Ben Wiles, Medical adviser at the Driver and Vehicle Licensing Authority, spoke on recent changes to driving regulations. He demonstrated that jobs traditionally verboten to people on insulin, such as driving buses or heavy goods vehicles, were now open, as long as the right checks, reviews and safeguards were in place.

What is the situation with regards to train drivers? There is currently no uniform agreement amongst the many disparate train companies in the UK. There are a few sporadic examples of enlightened occupational health experts giving the green light to train drivers on insulin in the UK (usually those with pre-existing type 2 diabetes progressing to insulin treatment), subject to regular review and regular specialist Consultant review from intensive type 1 specialists. As with airline pilots, however, there is no consensus on the use of continuous glucose monitoring in this context, given current concerns about its delays and validity.

Harry Phoolchund, an Occupational Health $(\mathrm{OH})$ Consultant, gave an overview

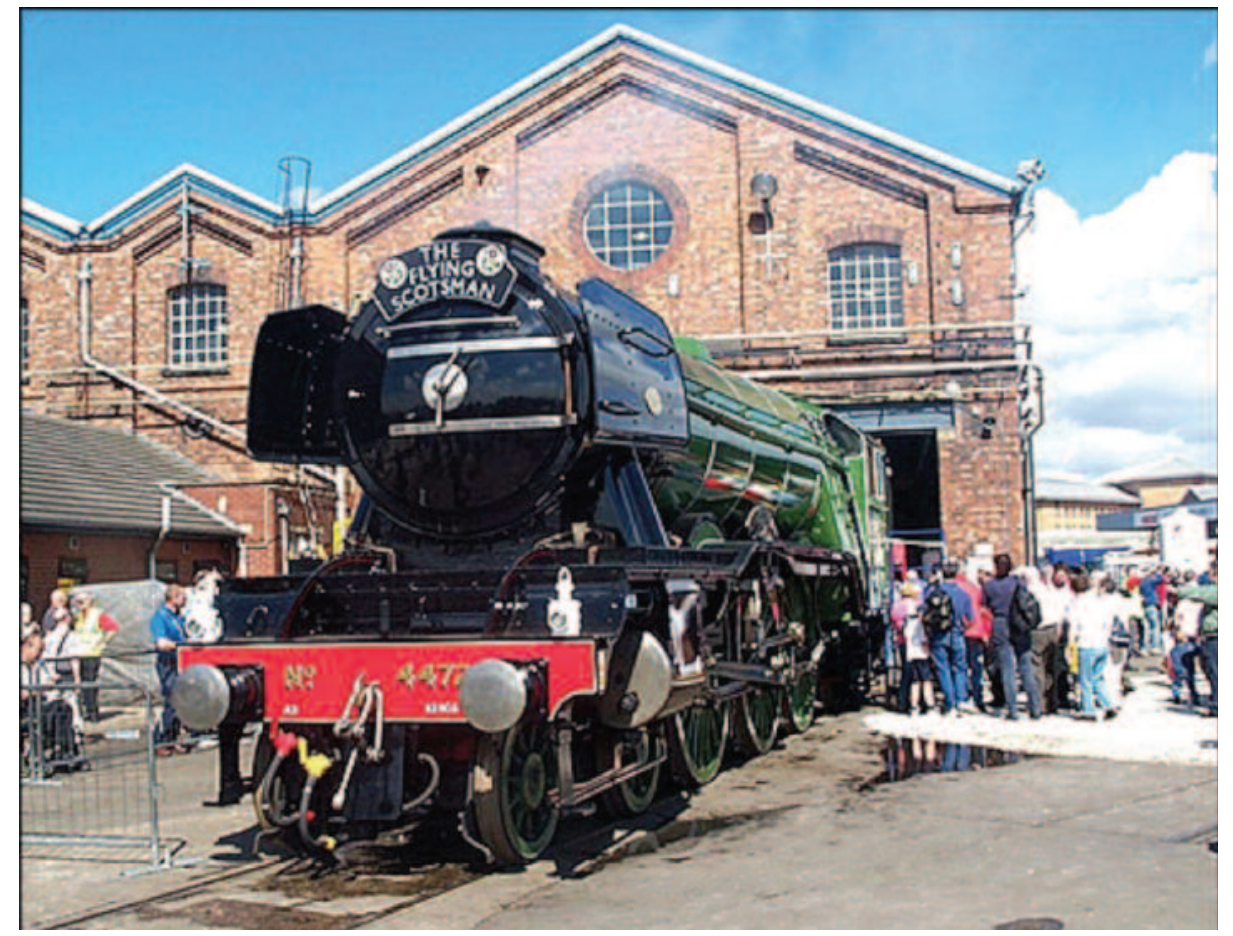

of recently developed occupational guidance on the fitness of individuals to drive a train and of the recent Southern Railway trial which involved close monitoring of several train drivers with diabetes. They underwent extensive capillary glucose testing over several months to assess the stability of their results and any concerning hypoglycaemia burden that they may experience. Despite some reassuring results, the train company itself has yet to make any formal decisions regarding their suitability to drive, and this is felt to be largely due to operational and logistical concerns. The worst case scenario, of course, is the potential risk of a driver having a hypoglycaemic episode whilst driving on the mainline, with the driver stranded in the cab and the passengers vulnerable to surrounding rail traffic. The general consensus amongst the $\mathrm{OH}$ doctors and diabetologists present was that this would be an unlikely scenario given the significant vetting, monitoring and reviews that would be taking place prior to someone with diabetes being able to drive a train. We await the formal decision with interest, as this is likely to have repercussions across the industry.

\section{References}

1. Shaw K. Setting occupational standards for insulin-treated diabetes at sea, on land and in the air. Practical Diabetes 2015;32:241-6. http://dx.doi.org/10.1002/pdi.1965

2. Grant P, Phoolchund $H$. Train driving and diabetes - keeping safety on track. Practical Diabetes 2015;32:200-03. http://dx.doi.org/10.1002/ pdi.1956

3. Simons R, Koopman H, Osinga M. Would you fly with a pilot on insulin? Lancet Diabetes Endocrinol 2014:2:446-7.

http://dx.doi.org/10.1016/S2213-8587(13)70197-9

Dr Paul Grant E-mail: editorpg@bjdvd.com

http://dx.doi.org/10.15277/bjdvd.2015.050 Br J Diabetes Vasc Dis 2015;15:195 